\title{
Cátedra Unesco para o desenvolvimento sustentável: o exemplo da Universidade Federal do Paraná (UFPR)
}

\author{
Paulo da Cunha LANA
}

A complexidade das relações entre o homem e a natureza expõe, de forma clara, os limites de quaisquer abordagens reducionistas para o trato da questão ambiental. Isto é particularmente verdadeiro quando se toma como referência a temática do meio ambiente e desenvolvimento. Neste contexto, há pelo menos duas décadas que diversas abordagens ditas integradoras, sejam elas multidisciplinares, interdisciplinares ou transdiciplinares, são discutidas em todo o mundo, tanto no plano epistemológico como metodológico.

É no marco dessas tentativas de se forçar a interação de distintas disciplinas para a compreensão e o manejo das complexas situações ambientais que a Universidade Federal do Paraná vem trabalhando desde 1987, com a criação de seu Núcleo Interdisciplinar de Meio Ambiente e Desenvolvimento (NIMAD), unidade interdepartamental e intersetorial que congrega atualmente mais de 50 departamentos da universidade. Uma das constatações iniciais deste Núcleo e dos pesquisadores e professores a ele associados foi a de que era necessário trazer para a academia práticas de reflexão e ação que se desenvolviam principalmente em outros âmbitos da sociedade, como os próprios órgãos públicos, federais, estaduais e municipais, além das organizações nãogovernamentais, voltados para o trato imediato de problemas de conservação e desenvolvimento. A discussão da questão ambiental e as tentativas de implantação destas abordagens integradoras não prosperavam na universidade por problemas estruturais, históricos e epistemológicos.

Instrumental para o avanço destas discussões sobre a temática ambiental foi a atribuição à UFPR de uma Cátedra UNESCO para o Desenvolvimento Sustentável. A finalidade geral do Plano de Cátedras da UNESCO, segundo sua própria constituição, é a transferência de conhecimentos, facilitando o acesso à informação e reduzindo as disparidades que separam países desenvolvidos e países em desenvolvimento no que se refere à ciência e tecnologia. As atividades preparatórias para a atribuição da cátedra culminaram em julho de 1993 com um amplo seminário internacional, que reuniu em Curitiba (Paraná) mais de 50 pesquisadores e professores originários de dezenas de universidades das Américas e da Europa. Na ocasião, foram discutidas e avaliadas formas de intercâmbio científico e cooperação interuniversitária como uma das bases essenciais para a formação de pessoal em cursos de alto nível.

Em 21 de março de 1994 foi oficialmente concedida à Universidade Federal do Paraná uma Cátedra UNESCO para o Desenvolvimento Sustentável. A

Cátedra da UFPR compreende, desde a sua concepção e implantação, um conjunto de atividades de formação, de pesquisa, de informação e de documentação. No centro destas atividades, estão a valorização dos recursos naturais e a análise das dimensões econômicas, sóciopolíticas e sócio-culturais do desenvolvimento sustentável em uma perspectiva interdisciplinar. Estes pressupostos devem, por sua vez, conduzir à aprendizagem de técnicas aplicáveis em distintas regiões e ao reforço das capacidades de formulação de políticas integradas de meio ambiente e desenvolvimento.

O Conselho Executivo da Cátedra é atualmente composto (dezembro/1997) pelo Prof. José Henrique de Faria, Reitor e pelo Prof. José Luiz Mercer, Pró-Reitor de Pesquisa e Pós-Graduação da UFPR, pelos professores Angela D. D. Ferreira (Dep. Ciências Sociais), Dimas Floriani (Departamento de Ciências Sociais), Francisco A. Mendonça (Dep. De Geografia), Paulo da Cunha Lana 
(Centro de Estudos do Mar), Raquel Negrelle (Dep. De Botânica) e Rodolfo José Angulo (Dep. De Geologia).

O Conselho Executivo é assessorado por um Conselho Diretor, composto por professores de universidades francesas que mantém intercâmbio com a UFPR: Profa. Magda Zanoni - Universidade Paris 7, Claude Raynaut - Diretor de Pesquisa do CNRS, Universidade Bordeaux 2, Prof. Yannis Tsiomis - Escola de Arquitetura Paris La Villette e Sra. Christine von Fürstenberg - Divisão de Ciências Humanas e Sociais da UNESCO.

A Cátedra possui também um Conselho Científico, composto por Dr. Enrique Leff - Coordenador - Rede de Formação Ambiental do PNUMA, Escritório Regional para América Latina e Caribe - México, Dr. Jacques Weber - Diretor de Pesquisa, Unidade de Pesquisa GREEN-CIRAD, França, Dr. Daniel Joseph Hogan diretor do NEPAM, Universidade de Campinas, São Paulo, Brasil, Dr. Juarez Rubens Brandão Lopes - Professor do Núcleo de Estudos de Políticas Públicas, Universidade de Campinas, São Paulo, Brasil, Dr. Paulo Freire Vieira - Professor da Universidade Federal de Santa Catarina, Florianópolis, Santa Catarina, Dra. Anamaria A. Bonin - Professora e Diretora do Departamento de Antropologia/ UFPR, Dr. Clóvis Pereira da Silva - Professor do Departamento de Matemática/UFPR, Dr. Hamilton Araújo Bicalho - Professor do Departamento de Física/ UFPR e Dr. José Miguel Rasia - Professor do Departamento de Sociologia/ UFPR.

A Cátedra permite igualmente o reforço da cooperação científica internacional, animando e coordenando ações conjuntas com uma rede de instituições, entre as quais se destacam a Universidade de Paris 7, a Universidade de Bordeaux 2 e a Escola de Arquitetura de Paris La Villette, além de várias universidades brasileiras, como a Universidade Federal do Rio de Janeiro e a Universidade de Campinas.

Os recursos iniciais da Cátedra ( US\$30.000,00) foram utilizados para o financiamento de missões de trabalho, montagem de infraestrutura logística e edição do primeiro número dos cadernos de Meio Ambiente e Desenvolvimento.

A principal atividade acadêmica desenvolvida na UFPR com a a chancela da Cátedra foi a criação de um curso de Pós-Graduação sensu stricto na área das ciências ambientais. O curso foi visualizado, desde a sua implantação em 1993, como um laboratório de reflexões teóricas e práticas concretas, lastreadas por amplos programas de pesquisa, para a abordagem dos problemas de Meio Ambiente e Desenvolvimento. A restrição do curso ao nível de doutorado está intimamente ligada a uma de suas principais diretrizes conceituais. Seu objetivo primário é a construção de uma visão integrada dos problemas pertinentes a meio ambiente e desenvolvimento. É ilusório esperar formar especialistas interdisciplinares em meio ambiente, no âmbito de programas acadêmicos forçosamente limitados a uns poucos anos. Um objetivo mais realista é capacitar profissionais que já possuem uma especialização para um trabalho de integração nas interfaces de um objeto novo. O objetivo não é o de criar novos especialistas ou disciplinas, mas sim promover a interação de profissionais já especializados em suas respectivas áreas de formação, com título de mestre ou experiência equivalente. Este curso, tanto quanto um processo de formação acadêmica, é também um espaço para a interação de profissionais já formados e especializados em suas respectivas áreas de conhecimento e, de preferência, já envolvidos profissionalmente com a temática do meio ambiente $\mathrm{e}$ desenvolvimento. O pressuposto é de que o doutorando já é um especialista na sua área. O conhecimento interdisciplinar deverá capacitá-lo a analisar problemas que não se explicariam pelo conhecimento unidisciplinar.

A segunda grande atividade chancelada pela Cátedra na UFPR é a pesquisa. Da mesma forma que o curso de doutorado procura fornecer os instrumentos teóricos, conceituais e práticos para o diálogo interdisciplinar, amplos programas de pesquisa tendem a ser o espaço para a prática concreta destas reflexões teóricas e de formação. O primeiro programa de pesquisa, que está sendo desenvolvido pela primeira turma do doutorado, com 16 alunos selecionados no final de 1993, denomina-se "Interações entre os processos produtivos, meio ambiente e qualidade de vida na região da Baía de Paranaguá/ PR: geração de propostas de desenvolvimento". A restrição do programa ao litoral norte do Paraná, em um país com problemas ambientais e desenvolvimento tão gritantes, teve razões de ordem prática. No plano do de- 
senvolvimento e meio ambiente, esta região é emblemática, porque ilustra de maneira quase didática a situação de conflito entre imperativos preservacionistas e uma realidade de subdesenvolvimento socio-econômico. No plano acadêmico, a restrição do trabalho a uma área relativamente pequena permitiu um maior controle do processo como um todo. Este programa foi consolidado financeiramente em 1994 através de sua aprovação pelo competitivo Programa de Apoio ao Desenvolvimento Científico e Tecnológico (PADCT-Ciências Ambientais), no valor de aproximadamente US\$ 500. 000,00. De maneira semelhante, a segunda seleção, com 14 alunos, tem como programa comum de pesquisa a análise da Gestão ambiental e condições de vida na Região Metropolitana de Curitiba”. Os 13 alunos da terceira turma, selecionada em 1997, desenvolverão suas atividades de formação e pesquisa relacionadas com o tema "Sustentabilidade: racionalidades, práticas e conflitos na gestão ambiental”.

Um terceiro conjunto de atividades que tem contado com decidido apoio da Cátedra é aquele relacionado com intercâmbios e cooperações. Neste contexto, os principais parceiros da UFPR têm sido as universidades de Bordeaux 2 e Paris 7, através do intercâmbio de professores e pesquisadores que participam ativamente do próprio curso de doutorado e dos programas de pesquisa a eles associados. Aos poucos outras instituições francesas foram se agregando ou colaborando ao projeto, sob a forma de convênios formais, como a École d'Architcture Paris La-Villette e o CIRAD-Green, ou da participação de seus professores ou pesquisadores, como a Universidade de Orleans.

No que se refere à difusão e informação, a Cátedra permitiu ainda a consolidação dos Cadernos de Desenvolvimento e Meio Ambiente, editados pela própria Universidade Federal do Paraná. Seu segundo volume, que trata da temática “ Universidade e Meio Ambiente: formação e pesquisa para atender à demanda social”, foi integralmente financiado com recursos da Cátedra. Este periódico pode exercer importante papel de divulgação em sua área de conhecimento, na medida em que há uma enorme escassez de periódicos destinados especificamente ao trato da problemática ambiental em países da América Latina. Finalmente, a Cátedra tem chancelado uma série de importantes eventos científicos de âmbito intercontinental, entre os quais se destacam o Workshop "O desenvolvimento de uma outra agricultura: acesso à terra e a meios de produção, a questão da fome e a integração social", realizado pela CAPESCOFECUB/UFPR, em Curitiba, de 30 de outubro a 1 de novembro de 1995, o Workshop "Ciências sociais, ciências naturais: meio ambiente e desenvolvimento". Universidade de Campinas, Universidade Federal do Paraná, EMBRAPA/CNRS, realizado em Campinas, em novembro de 1996 e as II Jornadas Científicas sobre Meio Ambiente, do Grupo Montevideo de Meio Ambiente e Desenvolvimento realizado na Universidade Federal do Paraná, de 8 a 11 de dezembro de 1996.

As expectativas do grupo em relação à Cátedra da UNESCO para os próximos anos, continuam centradas em atividades de formação, com o Prosseguimento das atividades regulares do Programa de Doutorado em Meio Ambiente e Desenvolvimento, com ênfase nas orientações, disciplinas e seminários a serem ministrados ou conduzidos por professores de outras universidades da América Latina e da Europa.

No que se refere à pesquisa, pretende-se dar prosseguimento aos programas das três turmas já selecionadas para o doutorado que envolvem, por sua vez, ativo intercâmbio com pesquisadores de outras universidades do país e do exterior. Por último, pretende-se consolidar a experiência editorial dos Cadernos de Desenvolvimento e Meio Ambiente, para que este periódico se firme como um importante agente de divulgação de atividades interdisciplinares em ciências ambientais no âmbito da América Latina. 